\title{
Seleção de ideótipos de espécies florestais de múltiplo uso em planícies fluviais do Baixo Amazonas, Pará
}

\author{
Gladys Beatriz MARTÍNEZ1, Moisés Mourão JUNIOR², Silvio Brienza JUNIOR
}

\begin{abstract}
RESUMO
A pesquisa objetivou selecionar ideótipos arbóreos de múltiplo uso, baseado em informaçôes etnobotânicas de comunidades ribeirinhas de planícies fluviais do Baixo Amazonas, Pará, para uso em sistemas silvipastoris. Como essas áreas foram antropizadas pela agricultura seguida da pecuária, esses sistemas são considerados alternativas viáveis para sua recuperação. Por meio de pesquisa participativa junto aos ribeirinhos, foi utilizado um questionário semi-estruturado para determinar as espécies arbóreas de maior importância para essas populaçóes, enfocando sua finalidade e formas de uso, consumidor destino e a abundância nas comunidades estudadas. As espécies florestais de interesse dos ribeirinhos concentraram-se nas frutíferas, para alimentação humana e animal, seguidas daquelas com função madeireira. Em sua grande maioria, essas espécies são utilizadas internamente na propriedade, não gerando produtos excedentes e foram consideradas, pelos entrevistados como de "grande" abundância na região.
\end{abstract}

PALAVRAS-CHAVE: Espécies florestais de múltiplo uso, planícies fluviais, população ribeirinha.

\section{Selection of multipurpose forest species ideotypes of the floodplains in the Low Amazon Basin, Pará}

\section{ABSTRACT}

The objective of this research was to select multipurpose arboreal ideotypes for use in silvipastoral systems. Selection of ideotypes was based on ethnobotanical information from riverside communities of Lower Amazon river floodplains, in Pará. Since these areas had been impacted by agriculture followed by ranching, the silvipastoral systems are considered viable alternatives for recuperating them. Through participatory research among the riverside inhabitants, a semi-structured questionnaire was used to determine the tree species of greatest importance to those populations, with focus on their purpose and forms of use, consumer destination and abundance in the communities studied. The forest species of interest to riverside people are most often fruit-producing species for human and animal food, followed by those for timber. The great majority of these species are employed internally on the property. They do not generate surplus products and were considered by the interviewees to be "greatly" abundant in the region.

KEYWORDS: Multipurpose forest species, floodplains, riverside population.

1 Empresa Brasileira de Pesquisa Agropecuária, Embrapa, E-mail: gladys@cpatu.embrapa.br

2 Empresa Brasileira de Pesquisa Agropecuária, Embrapa Amazônia Oriental, E-mail: mmourao@cpatu.embrapa.br

${ }^{3}$ Empresa Brasileira de Pesquisa Agropecuária, Embrapa Amazônia Oriental, E-mail: brienza@cpatu.embrapa.br 


\section{INTRODUÇÃO}

Durante a época colonial e ao longo de quase 150 anos de predomínio do mercantilismo, a economia da Amazônia teve como foco as planícies fluviais de onde foram extraídos produtos madeireiros, não madeireiros, peixes e quelônios (Lima, 2005). Posteriormente, incentivos governamentais propiciaram o desenvolvimento da agricultura liderada pelo cultivo da juta, seguida da pecuária em pastagens naturais. Entre as décadas de 1970 e 1980, a crise da juta (Homma, 1998) incentivou a expansão da pecuária surgindo novos ecossistemas antropogênicos, como capoeiras e pastagens cultivadas. Essas pastagens são, até hoje, fundamentais no desenvolvimento da bovino e bubalinocultura pelo elevado potencial de produção e valor nutritivo.

A agricultura seguida da pecuária propiciou a redução da cobertura arbórea alterando as características das planícies fluviais por acelerar a erosão do solo, principalmente pelo fenômeno conhecido como "terras caídas" (Falesi e Silva, 1999), fortemente influenciado pelo fluxo e refluxo anual do nível da água dos rios que inunda suas margens (Bittencourt e Amadio, 2007).

A cheia dos rios e a conseqüente deposição anual de sedimentos definem a geomorfologia das planícies fluviais, sua fauna, flora e mesmo os seus padrōes de ocupação humana (Queiroz, 2005). As populaçóes tradicionais que vivem nessas áreas (os ribeirinhos) possuem amplo conhecimento sobre a floresta e têm hábitos alimentares e padrões de moradia diferentes das populaçóes de regióes de terra-firme. Os ribeirinhos exploram boa parte dos recursos naturais onde o extrativismo se apresenta estratégico para sua sustentabilidade.

Pela fragilidade das planícies fluviais e seu baixo grau de resiliência, a remoção da cobertura vegetal pode levar a perda total do habitat, face a importância ecológica e estrutural que as plantas desempenham na manutenção desse ecossistema (Almeida et al., 2004). A reduçấo das populaçôes de peixes que se alimentam de frutos caídos de árvores no período das enchentes (Lima, 2005) passa a influenciar na composição florística das terras inundáveis, pois os peixes são responsáveis por grande parte da distribuição de sementes nessas áreas (Dubois, 1996).

Com as planícies fluviais desmatadas, as populaçóes tradicionais se vêem desabastecidas de importantes fontes de alimento e de outros usos: a pesca e os frutos de algumas espécies são fontes de alimento humano, os frutos também alimentam peixes e animais domésticos, a madeira é usada para benfeitorias e lenha (Goulding et al., 1996; Canto, 2007), troncos, galhos e fibras são transformados em materiais básicos de uso doméstico e artesanato (Costa, 2008) e algumas árvores se destacam pela aptidão para sombra. Das folhas e raízes de algumas espécies, os povos ribeirinhos extraem ungüentos e pomadas medicinais, prática que perdeu muito espaço pelo desenvolvimento da indústria química. Entretanto, uma crescente redescoberta do valor das plantas medicinais tem sido observada em decorrência não só de certos efeitos colaterais imprevistos de muitos remédios artificiais, embora o uso incorreto das plantas também possa causá-los (Siqueira, 2008).

Dada a importância das árvores nas planícies fluviais, os sistemas silvipastoris, diversificados e multi-estratificados nos quais os cultivos arbóreos são explorados com as gramíneas forrageiras, são de grande potencial para a recuperação dessas áreas por conciliarem a aptidão pastoril à recomposiçấo da paisagem natural (Veiga et al., 2000; Dias-Filho, 2007).

A manutenção ou plantio de árvores de uso múltiplo normalmente enfoca o interesse econômico, podendo ser motivada por interesse ecológico (Nair, 1993). Nas planícies fluviais ocorrem espécies de múltiplos usos e de diferentes valores da paisagem. Antes do inicio de qualquer programa de restauração florestal, é importante priorizar espécies que satisfaçam náo somente as necessidades presentes e futuras dos agricultores (Montes e Weber, 1997; Almeida et al., 2004), como também selecionar ideótipos (melhor estrutura de uma planta para otimizar a produçáo, Huxley, 1999) que se adeqüem as finalidades do sistema silvipastoril proposto.

Grande parcela das áreas preservadas do território brasileiro é habitada por comunidades rurais "tradicionais", como os ribeirinhos, que corporificam um modo de vida tradicionalmente harmonioso com o ambiente (Arruda, 1997). A inclusão da perspectiva das populaçôes rurais, reconhecendo sua identidade e valorizando o seu saber através das experiências acumuladas por gerações (Grenier, 1999), possibilitam a seleçâo de espécies florestais de importância econômica, social, moral (Sheil et al., 2003) e ecológica desses povos.

Dessa forma, esta pesquisa objetivou selecionar ideótipos arbóreos de espécies de múltiplo uso, baseado em informações etnobotânicas, a serem cultivadas nas planícies fluviais do Baixo Amazonas para a recomposição da paisagem natural considerando as prioridades de utilização das comunidades locais.

\section{MATERIAL E MÉTODOS}

A pesquisa foi realizada em 13 comunidades rurais de planícies fluviais, banhadas pelo rio Amazonas e afluentes, no Baixo Amazonas, Estado do Pará, em julho de 2004. Foram preenchidos 18 formulários, sendo alguns individuais, outros coletivos. As comunidades ribeirinhas estão localizadas nos municípios de Santarém (Fé em Deus do Ituqui, Igarapé da Praia, Palhão, Paraná - Fé em Deus e Saracura), Prainha (Ipanema, Pacoval e Santa Maria - Fé em Deus) e Monte 
Alegre (Bom Jardim, Cacoal Grande, Piapó, Remanso e Santa Rita). Os dados climáticos são procedentes da estação meteorológica localizada na área de Cacoal Grande, Monte Alegre, Pará. As temperaturas médias anuais estão entre 27 e $28^{\circ} \mathrm{C}$, umidade relativa do ar entre 78 a $85 \%$, velocidade do vento cerca de $2 \mathrm{~km} / \mathrm{h}$ e precipitaçáo pluvial média de 2.000 mm (LbaSantarém, 2006).

$\mathrm{O}$ instrumento utilizado para a coleta de dados junto às comunidades ribeirinhas foi um questionário semi-estruturado que permite a junção de perguntas dirigidas fechadas (ou estruturadas) e abertas, possibilitando ao entrevistado discorrer sobre o tema proposto, sem respostas específicas ou condiçóes prefixadas pelo pesquisador (Araújo e Rocha, 2007). As questóes elaboradas buscaram determinar as espécies arbóreas de maior importância para as populaçóes locais e embasadas nos seguintes aspectos: (i) finalidade do uso (fonte de alimento humano e animal, medicina popular, construçóes e outros); (ii) destino do consumo (humano, peixes, animais domésticos ou outros); (iii) formas de uso (árvore como um todo, folha, fruto, casca, tronco, semente, outros); e (iv) ocorrência atual (abundância).

As diversas espécies arbóreas declaradas pelos entrevistados foram classificadas em função da forma de uso (frutos, folhas, sementes, madeira, casca, árvore e outros), finalidade de uso (madeireiro, alimentação, medicinal, etc.), consumidordestino (humano ou animal) e o nível de abundância sob a ótica dos entrevistados, referente a sua comunidade (pequena, média e grande), arranjando as espécies arbóreas em grupos de maior afinidade. Para este objetivo foi utilizada a técnica multivariada de análise de agrupamento (cluster analysis). Para polarizar as variáveis em grupos de maior discriminância e buscando a ordenação dos tratamentos, foi aplicada uma análise de Componentes Principais (PCA), identificando as variáveis mais importantes no espaço de cada componente principal (CP). A regra de Kaiser foi adotada para determinação dos auto-valores e um limiar de $|\lambda| \geq 0,40$ para os auto-vetores (Manly, 1994; Johnson e Wichern, 1998). A disposição das espécies em dendrograma foi utilizada para definir os agrupamentos entre elas, os quais são sintetizados com os diferentes usos predominantes das espécies.

Todas as análises foram conduzidas com o auxílio da planilha eletrônica Excel e dos pacotes estatísticos SAS System ${ }^{\circledR}$ e Statistica 5.5 (C) (SAS Institute, 1990; Statsoft Inc. Statistica, 2001).

\section{RESULTADOS}

O diagnóstico realizado identificou as espécies florestais de múltiplo uso consideradas de interesse dos moradores da região (Tabela 1). Dentre as espécies declaradas pelos ribeirinhos entrevistados, a jenipapeiro apresentou maior freqüência, sendo mencionada por todos os informantes e o uso da espécie marizeiro-verde foi declarado pelo menor número de informantes (Figura 1).

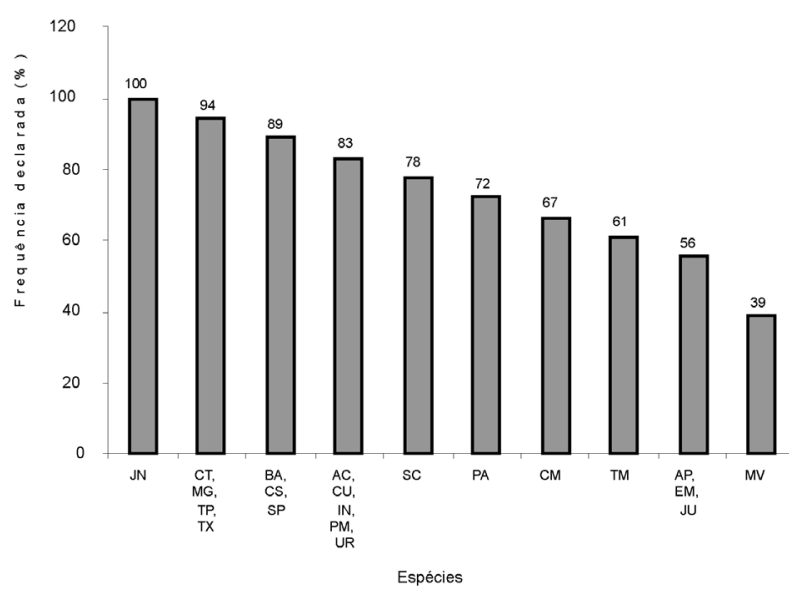

Figura 1 - Freqüência com que as espécies florestais foram declaradas pelos ribeirinhos na região do Baixo Amazonas - Pará.

Tabela 1 - Espécies florestais identificadas pela pesquisa em 13 comunidades de uma região de planície fluvial do Baixo Amazonas - Pará.

\begin{tabular}{|c|c|c|c|c|}
\hline & Nome vulgar & Nome científico & Família & Sigla \\
\hline 1 & Açacuzeiro & Hura crepitans & Euphorbiaceae & $A C$ \\
\hline 2 & Apuizeiro & Ficus sp. & Moraceae & AP \\
\hline 3 & Bacurizeiro & Platonia insignis. & Clusiaceae & $\mathrm{BA}$ \\
\hline 4 & $\begin{array}{l}\text { Castanheira-de- } \\
\text { macaco }\end{array}$ & Couroupita guianenses & Lecythydaceae & $\mathrm{CM}$ \\
\hline 5 & $\begin{array}{l}\text { Castanheira- } \\
\text { sapucaia }\end{array}$ & Lecythis Pisonis camb. & Lecythydaceae & CS \\
\hline 6 & Catauarizeiro & Crataeva benthamii & Capparaceae & CT \\
\hline 7 & Cuieira & Crescentia cuiete & Bignoniaceae & $\mathrm{CU}$ \\
\hline 8 & Embaubeira & Cecropia sp & Cecropiaceae & EM \\
\hline 9 & Ingazeiro & Inga edulis & Fabaceae & IN \\
\hline 10 & Jauarizeiro & Astrocaryum jauari & Arecaceae & JU \\
\hline 11 & Jenipapeiro & Genipa americana & Rubiaceae & JN \\
\hline 12 & $\begin{array}{l}\text { Marizeiro-verde/ } \\
\text { Seroieira }\end{array}$ & Piranhea trifoliata & Euphorbiaceae & MV \\
\hline 13 & Mungubeira & Bombax munguba & Bombaceae & MG \\
\hline 14 & Paricazeiro & Schizolobium amazonicum & Leguminosae & $\mathrm{PA}$ \\
\hline 15 & Pau-mulateiro & Pentaclethra macroloba & Fabaceae & PM \\
\hline 16 & Sapupireira & Andira inermis & Fabaceae & SP \\
\hline 17 & Socorozeiro & Eugenia brachypoda & Myrtaceae & SC \\
\hline 18 & Tamanqueira & Corallodendron fuscum & Leguminosae & $\mathrm{TM}$ \\
\hline 19 & Taperebazeiro & Spondias mombin & Anacardiaceae & TP \\
\hline 20 & Taxizeiro & Tachigalia paniculata & Leguminosae & TX \\
\hline 21 & Uruazeiro & Cordia tetrandra & Boraginaceae & UR \\
\hline
\end{tabular}


Tabela 2 - Freqüência de citação para formas de uso, finalidade de uso e consumidor-destino das espécies florestais indicadas pelos entrevistados.

\begin{tabular}{|c|c|c|c|c|c|c|c|c|c|c|c|c|}
\hline \multirow[b]{2}{*}{ Espécie } & \multicolumn{7}{|c|}{ Formas de uso - U } & \multicolumn{4}{|c|}{ Consumidor-destino } & \multirow[b]{2}{*}{ Finalidade de uso } \\
\hline & FRU & $\mathrm{FL}$ & SEM & MAD & CAS & ARV & OUT & HUM & PEIX & $A D$ & AS & \\
\hline Açacuzeiro & 2 & & & 2 & 8 & 1 & & 11 & 2 & & & $\begin{array}{l}\text { Alimento animal; medicinal: anti-inflamatório/ } \\
\text { cancer/diarréia; madeira; sombra }\end{array}$ \\
\hline Apuizeiro & 10 & 1 & & & & & 2 & 4 & 8 & 3 & 3 & Alimento animal; medicinal: torção muscular \\
\hline Bacurizeiro & 16 & & 2 & & & & & 16 & 13 & 9 & 15 & Alimento e produção de mudas \\
\hline Cast. macaco & 12 & & & & & & & & 2 & 11 & 6 & Alimento animal \\
\hline Cast. Sapucaia & 16 & & 3 & 3 & 3 & & 1 & 16 & & 4 & 4 & Alimento; madeira; carvão; ouriço: artesanato \\
\hline Catauarizeiro & 17 & & & 1 & 6 & & & 2 & 17 & 3 & 2 & $\begin{array}{l}\text { Alimento animal; medicinal: picada de cobra, } \\
\text { reumatismo }\end{array}$ \\
\hline Cuieira & 18 & & & & & & & 18 & & 1 & & Alimento animal; utensílio doméstico \\
\hline Embaúbeira & 4 & 2 & & & & 7 & 1 & 6 & 3 & 1 & 2 & $\begin{array}{c}\text { Medicinal: pressão alta; abortivo animal; } \\
\text { marombas }\end{array}$ \\
\hline Ingazeiro & 15 & & & & & & & 13 & 3 & 4 & 4 & Alimento \\
\hline Jauarizeiro & 10 & & & & & & & & 10 & 3 & 2 & Alimento animal \\
\hline Jenipapeiro & 18 & & & & & & & 18 & 4 & 15 & 12 & Alimento; medicinal: anemia, icterícia \\
\hline Mari verde/seroieira & 7 & & & & & & & 7 & 1 & 2 & 3 & Alimento animal \\
\hline Mungubeira & 14 & & & 2 & 3 & & 9 & 12 & 15 & & & $\begin{array}{c}\text { Envira: fabricação de cordas, roupas típicas; adubo } \\
\text { orgânico }\end{array}$ \\
\hline Paricazeiro & 1 & & & 13 & & & & 13 & & & & Lenha e estaca; mudas \\
\hline Pau mulateiro & & & & 15 & & & & 15 & & & & Construção: pilar, esteio, estaca; lenha \\
\hline Sapupireira & 3 & 1 & & 6 & 1 & 10 & & 15 & 1 & 1 & 5 & $\begin{array}{l}\text { Alimento animal; medicinal: inflamação, vermífugo; } \\
\text { sombra; Ienha }\end{array}$ \\
\hline Socorozeiro & 14 & & & & & & & 9 & 14 & 7 & 3 & Alimento animal \\
\hline Tamanqueira & & & & 4 & & 8 & & 11 & & & & Lenha, estacas; sombra \\
\hline Taperebazeiro & 17 & & & & 3 & & & 17 & 6 & 6 & 5 & $\begin{array}{l}\text { Alimento; medicinal: anti-inflamatório/cicatrizante/ } \\
\text { diarréia; sombra }\end{array}$ \\
\hline Taxizeiro & 1 & & & 16 & 3 & & & 17 & 1 & & 1 & Madeira; mudas \\
\hline Uruazeiro & 14 & 1 & & & & & & 1 & 14 & 3 & 6 & Alimento animal \\
\hline
\end{tabular}

FRU- fruto; FL- folha; SEM- semente; MAD- madeira; CAS- casca; ARV- árvore; OUT- outras partes; HUM- humano; PEIX- peixe; AD- animal doméstico; AS- animal silvestre. FRU-fruit; FL-sheet; SEM-seed; MAD-wood; CAS-shell; ARV-tree; OUT-other parties; HUM-human; PEIX-fish; AD-domestic animal; AS-animail wild.

As formas de uso dessas espécies (frutos, folhas, sementes, madeira, casca, a árvore como um todo, outros), finalidades de uso (alimentação, madeireira, medicinal, etc.) e o consumidordestino (humano ou animal) foram relacionados de acordo com as declaraçóes dos ribeirinhos da região (Tabela 2).

Das espécies levantadas, $71 \%$ foram declaradas com finalidade de uso alimentício, seja de forma direta para consumo humano, normalmente "in natura", ou através dos animais domésticos, caça e peixes que se alimentam dos frutos dessas espécies, tornando-se posteriormente, fontes de alimento das populaçóes locais.

A madeira é utilizada para currais, lenha e pequenas obras. Outras partes da árvore, como folhas, sementes e casca são utilizadas normalmente na medicina regional e a árvore como um todo, para sombreamento, amenizando as altas temperaturas da várzea.

A análise de agrupamento baseada nas formas de uso (U) permitiu identificar quatro grupos de espécies florestais (Figura 2 e Tabela 3). Estes agrupamentos foram caracterizados pelas formas de uso a partir da ordenação fatorial a qual reduziu

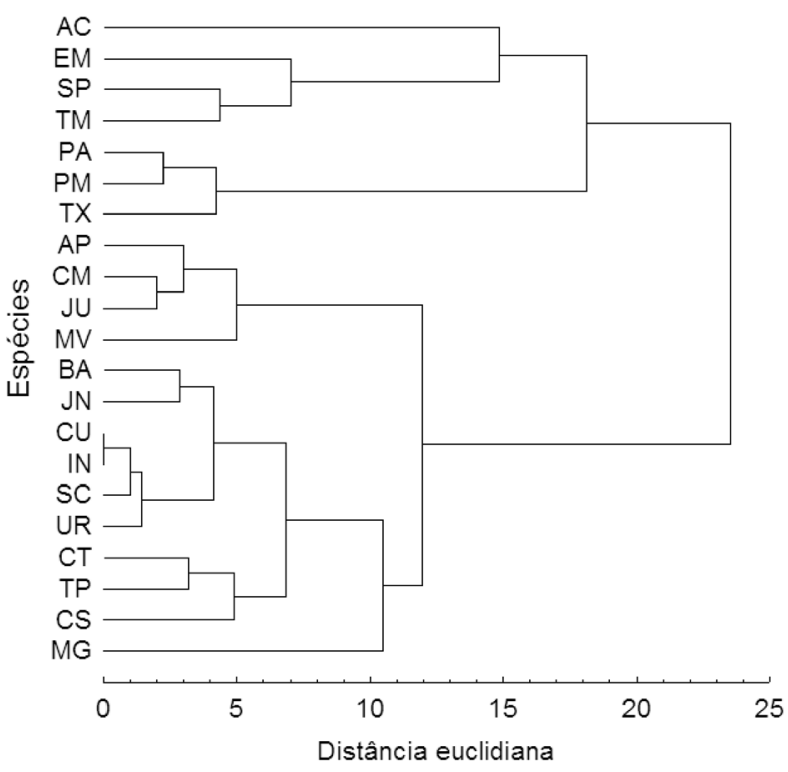

Figura 2 - Dendrograma de dissimilaridade entre as formas de uso das espécies declaradas pelos ribeirinhos nas entrevistas estruturadas. 
Tabela 3 - Freqüência média e extrema observada entre as espécies florestais constituintes dos agrupamentos relativos as formas de uso (U).

\begin{tabular}{|c|c|c|c|c|c|c|c|}
\hline \multirow{2}{*}{ Agrupamentos de espécies } & \multicolumn{7}{|c|}{ Formas de uso (U) } \\
\hline & Frutos & Madeira & Casca & Folhas & Sementes & Árvore & Outros \\
\hline $\begin{array}{l}\mathrm{U}_{1} \text { : açacuzeiro, embaubeira, sapupireira, } \\
\text { tamanqueira }\end{array}$ & $3[2-4]$ & $4[2-6]$ & $6[1-10]$ & $2[1-2]$ & & 7 [1-12] & 1 \\
\hline $\begin{array}{l}\mathrm{U}_{2} \text { : apuizeiro, castanheira-de-macaco, } \\
\text { jauarizeiro, marizeiro-verde }\end{array}$ & 10 [7-12] & & & 1 & & & 2 \\
\hline $\mathrm{U}_{3}$ : paricazeiro, pau mulateiro, taxizeiro & 1 & $15[13-16]$ & $3[3-3]$ & & & & \\
\hline $\begin{array}{l}\mathrm{U}_{4} \text { : bacurizeiro, castanheira-sapucaia, } \\
\text { catauarizeiro, cuieira, ingazeiro, } \\
\text { jenipapeiro, mungubeira, socorozeiro, } \\
\text { taperebazeiro, uruazeiro }\end{array}$ & 16 [14-18] & 2 [1-3] & $4[3-6]$ & 1 & 3 [2-3] & & $5[1-9]$ \\
\hline
\end{tabular}

Valores em [] - mínimo e máximo das freqüências observadas entre as espécies constituintes dos agrupamentos.

Figures in [ ] - the minimum and maximum rates observed among species of constituent groups.

suas freqüências a três componentes principais que explicaram cerca de $70 \%$ da variação global (Figura 3). No componente principal PCA-I, que explicou $28,7 \%$ da variação global dos dados, foram significativos os auto-vetores referentes à freqüência de uso de frutos, sob orientação positiva e árvore e madeira, sob orientação negativa. Já no PCA-II, que explicou $22,4 \%$ da variaçáo global dos dados, foram significativos os auto-vetores referentes ao uso de folhas, com orientação positiva e de madeira, sob orientação negativa. No PCA-III, que explicou 19,3\% da variação global dos dados, foram significativos os auto-vetores referentes a outros usos e casca, ambos com orientação positiva.

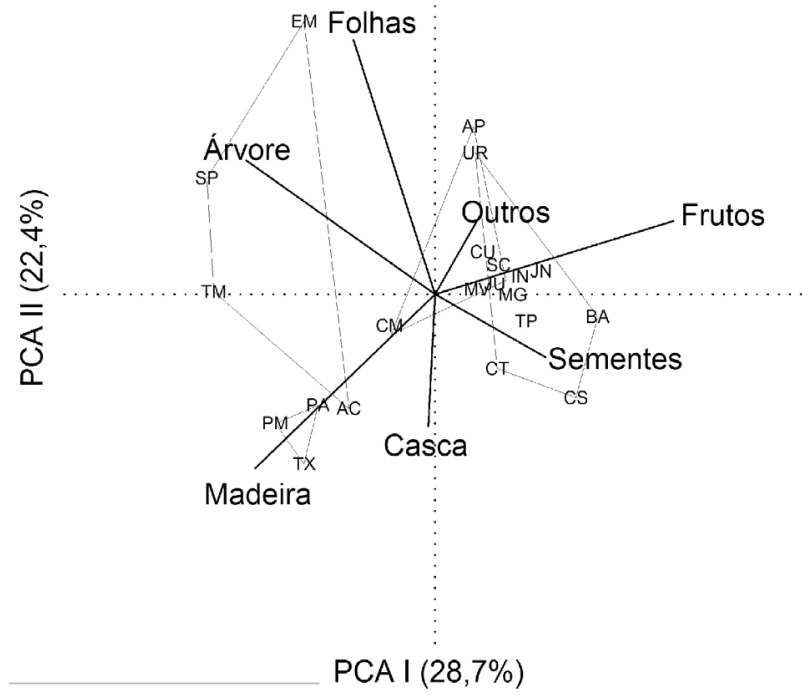

Figura 3 - Escores das espécies florestais, declaradas pelos ribeirinhos, obtidos em função da freqüência relativa das formas de uso. PCA - análise de componentes principais.

As espécies reunidas em $\mathrm{U}_{1}$ representam a árvore como um todo, com destaque para o uso da casca e madeira; no $\mathrm{U}_{2}$, espécies com uso basicamente de frutos; no $\mathrm{U}_{3}$, espécies com uso representado predominantemente pela madeira; e no $\mathrm{U}_{4}$ espécies de múltiplo uso, mas com amplo predomínio para frutos.
As informaçóes provenientes das entrevistas destacaram como consumidores-destino das espécies florestais, os humanos, animais domésticos e silvestres e peixes, estando sua finalidade vinculada as diferentes formas de uso. A partir da análise de agrupamento, o consumidor-destino foi agrupado em: $\mathrm{G}_{1}$ (ingazeiro, taperebazeiro, marizeiro-verde, castanheira-sapucaia, cuieira): são árvores de finalidade basicamente frutífera, de uso predominantemente humano; $\mathrm{G}_{2}$ (bacurizeiro, socorozeiro, jenipapeiro): também frutíferas, porém de uso amplo, utilizadas com freqüência por humanos, animais domésticos, silvestres e peixes; $\mathrm{G}_{3}$ (catauarizeiro, uruazeiro, apuizeiro, jauarizeiro, mungubeira, castanheirade-macaco): considerado um grupo de função ecológica, no qual as espécies florestais apresentaram maior freqüência no consumo de frutos pelos animais silvestres e peixes; $G_{4}$ (embaubeira, sapupireira, tamanqueira, açacuzeiro): grupo com finalidade madeireira, de uso múltiplo, focada para uso da madeira e casca com destino humano; $\mathrm{G}_{5}$ (paricazeiro, taxizeiro, pau mulateiro): espécies com enfoque madeireiro e uso específico por humanos (Tabela 4).

Outro resultado obtido pela pesquisa refere-se a abundância com que essas espécies ocorrem na região. Sob a ótica dos entrevistados e mediante a análise de agrupamento, a intensidade de ocorrência das espécies florestais mostrou a existência de três grupos (Figura 4) e a ordenação fatorial da freqüência de classes de abundância resultou em dois agrupamentos por componentes principais (CPA). O primeiro, PCA-I, captou de $66 \%$ da variação global e é representado pelas espécies que apresentaram "grande" abundância (auto-vetores com orientação negativa) e "média" abundância (auto-vetores com orientação positiva) (Figura 5). Já o PCA-II, que captou $29 \%$ da variação global dos dados, apresentou espécies com "pequena” abundância (auto-vetores com orientação negativa) e "média" abundância (auto-vetores com orientação positiva).

Baseado nas análises de agrupamento e componentes principais, a freqüência com que as espécies florestais ocorrem nas comunidades estudadas, sob a ótica dos entrevistados, 
Tabela 4 - Freqüência de respostas dos agrupamentos das espécies florestais declaradas relativas ao consumidor destino.

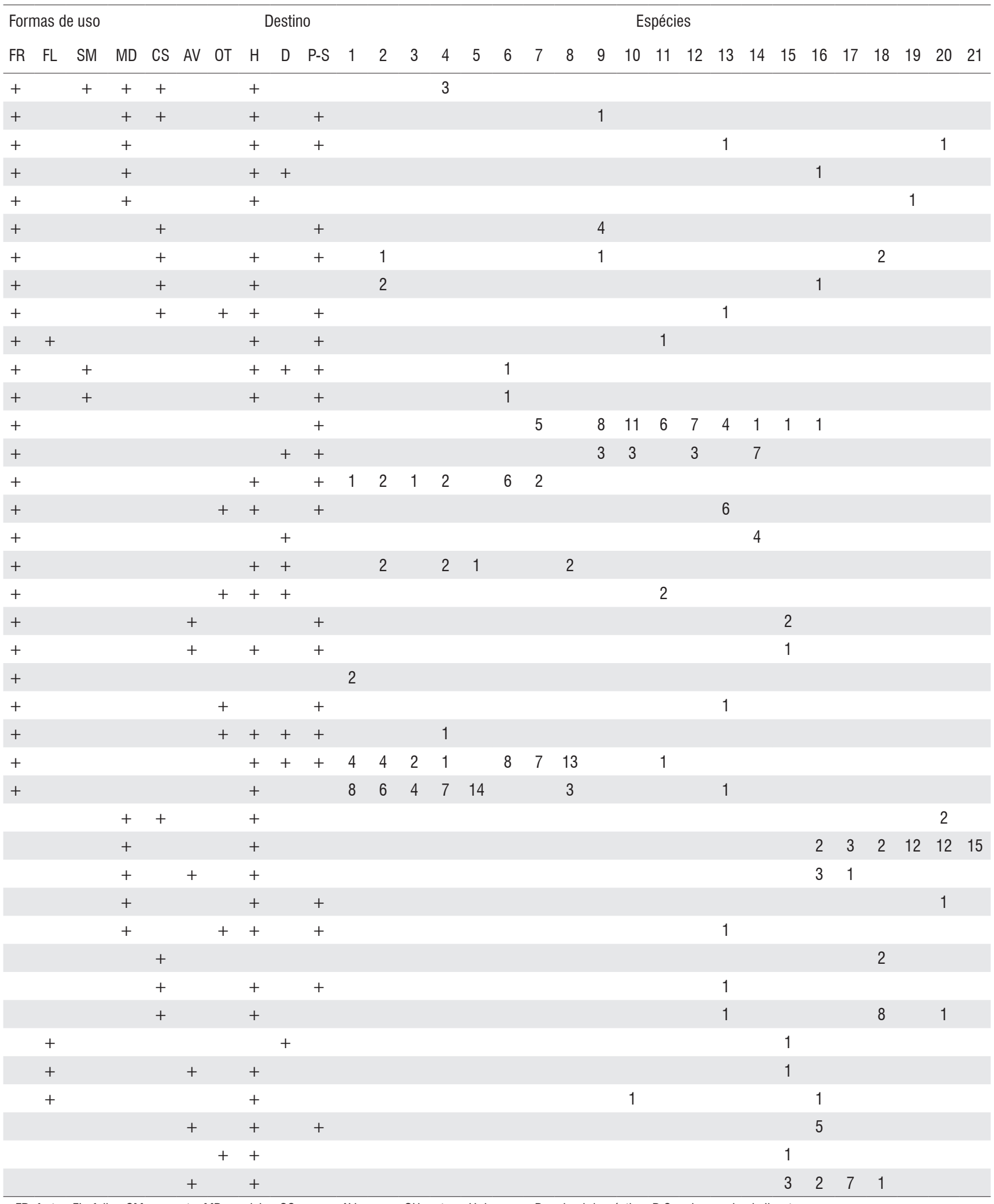

FR: fruto; FL: folha; SM: semente; MD: madeira; CS: casca; AV: arvore; OU: outros; H: humano; D: animal doméstico; P-S: peixe e animal silvestre.

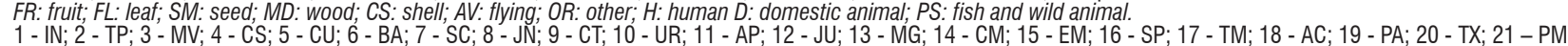




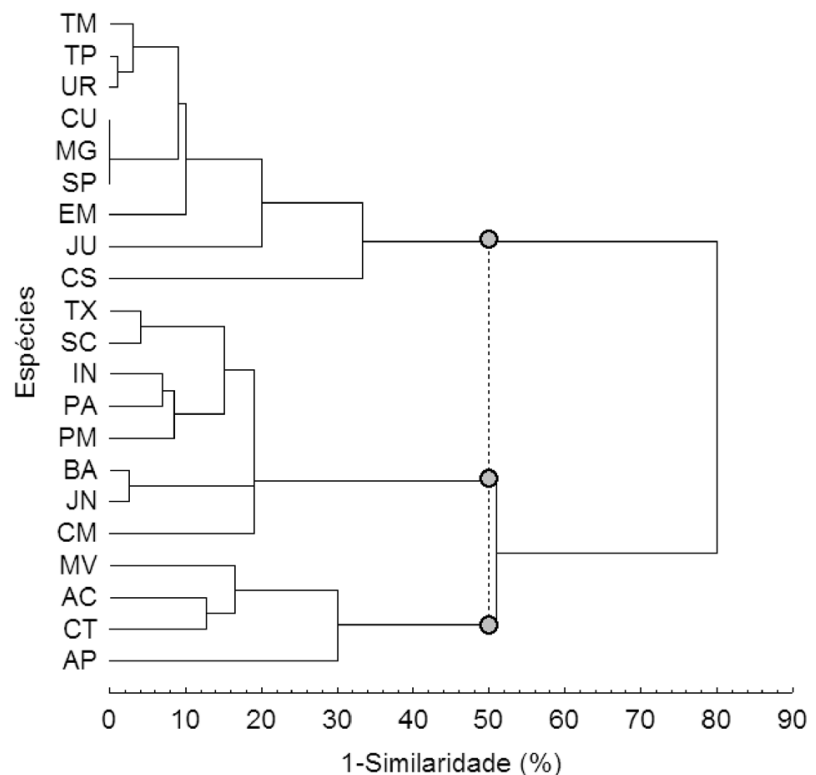

Figura 4 - Dendrograma de dissimilaridade entre as espécies florestais assinaladas nas entrevistas estruturadas.

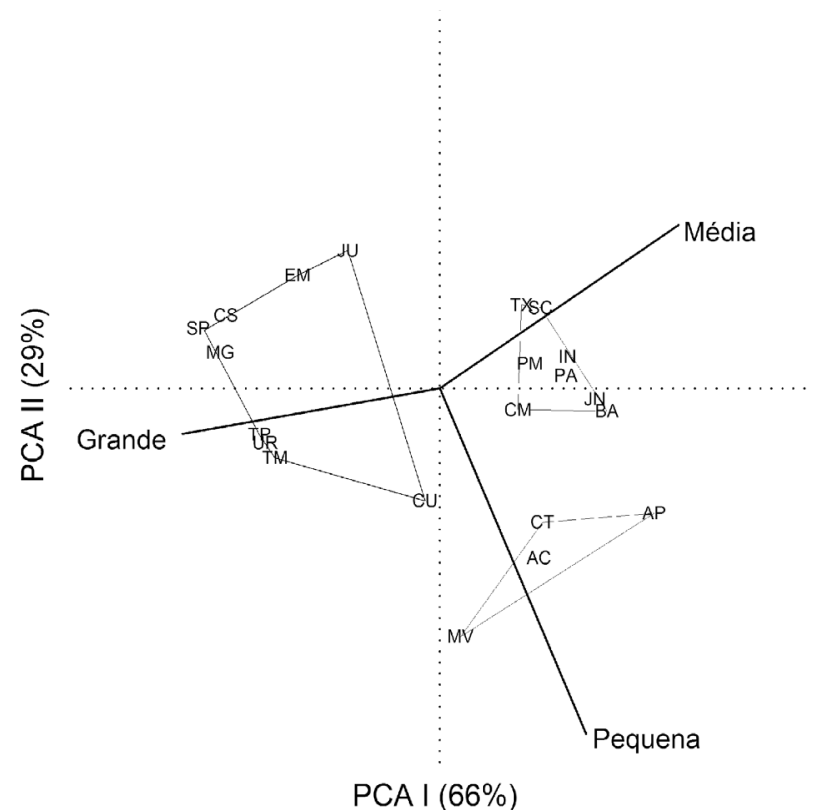

Figura 5 - Escores das espécies florestais obtidos em função da freqüência relativa das classes de abundância.

apresentam predomínio de "grande" abundância, seguida da condição de "média" abundância, que juntas são declaradas por mais de $80 \%$ dos entrevistados (espécies dos grupos $\mathrm{A}_{2} \mathrm{e}$ $\mathrm{A}_{3}$ ) (Tabela 5). Entretanto, as espécies listadas no agrupamento $\mathrm{A}_{1}$ são consideradas de pequena abundância por $38 \%$ dos ribeirinhos, ou seja, em algumas comunidades estudadas são pouco freqüentes.

\begin{tabular}{|c|c|c|c|c|c|}
\hline & & \multicolumn{4}{|c|}{ Abundância das espécies (\%) } \\
\hline $\begin{array}{l}\text { Grupos de } \\
\text { abundância }\end{array}$ & Espécies & $\begin{array}{c}\text { Sem } \\
\text { resposta }\end{array}$ & Pequena & Média & Grande \\
\hline$A_{1}$ & $\begin{array}{l}\text { Açacuzeiro, apuizeiro, } \\
\text { catauarizeiro, marizeiro- } \\
\text { verde }\end{array}$ & 4 & 38 & 9 & 49 \\
\hline $\mathrm{A}_{2}$ & $\begin{array}{l}\text { Bacurizeiro, castanheira- } \\
\text { de-macaco, ingazeiro, } \\
\text { jenipapeiro, paricazeiro, } \\
\text { pau mulateiro, } \\
\text { socorozeiro, taxizeiro }\end{array}$ & 2 & 18 & 41 & 39 \\
\hline $\mathrm{A}_{3}$ & $\begin{array}{c}\text { Castanheira-sapucaia, } \\
\text { cuieira, embaubeira, } \\
\text { jauarizeiro, mungubeira, } \\
\text { tamanqueira, sapupireira, } \\
\text { taperebazeiro, uruazeiro }\end{array}$ & 0 & 7 & 8 & 85 \\
\hline
\end{tabular}

\section{DISCUSSÃO}

O envolvimento de comunidades ribeirinhas na retomada do conhecimento tradicional proporciona aos produtores exercerem um papel ativo no processo de seleção das espécies para reflorestamento de áreas antropizadas (Montes \& Weber, 1997; Garrafiel et al., 1999; Franke et al., 2000), de forma a aproveitar, ao máximo, os recursos locais existentes (Projeto Iara, 1996).

As inúmeras informaçóes da abordagem participativa permitem identificar que, independente do universo de espécies florestais levantadas, a forma de uso foi concentrada em dois segmentos: frutíferas $\left(G_{1}, G_{2}, G_{3}\right)$ para consumo humano e/ou animal, e madeireiro $\left(\mathrm{G}_{4}, \mathrm{G}_{5}\right)$, para usos múltiplos na propriedade rural (medicinal, lenha, instalaçóes e outros).

O número expressivo de espécies frutíferas, citadas por mais de $70 \%$ dos entrevistados, vinculadas a alimentação humana, fortalece a teoria de que árvores com esse fim são fundamentais para a sobrevivência dos ribeirinhos (Souza, 2002). Entretanto, a suplementação alimentar por essas espécies pode não ser explicitamente intencional, sugerindo que o aproveitamento mais intenso dessa fonte nutricional suplementar esteja relacionada com o baixo poder aquisitivo dessas populaçóes (Semedo \& Barbosa, 2007), o que permite supor também que a distância, a ineficiência e o custo do transporte rodofluvial dessas áreas até os centros urbanos dificultam a aquisição de outras fontes de alimento.

O jenipapo, declarado por todos os informantes como um fruto de importância local, é considerado uma excelente fonte de alimentaçáo suplementar pelo elevado valor nutricional, contendo $17,5 \%$ de ácido linoleico e 4,1\% no balanceamento de Ômega-6 com Ômega-3 (Costa, 2008). É uma espécie cuja 
árvore também é destacada por Salvador (1986) pela alta taxa de sobrevivência em terras inundáveis. O bacuri, do mesmo grupo do jenipapo, é uma fruta nativa da regiâo amazônica e do nordeste do país, de uso popular é encontrada nas feiras livres. Sua polpa doce é utilizada "in natura" ou em sorvetes e sucos, tendo grande aceitaçáo nas áreas de ocorrência natural da espécie. Além do consumo humano, o fruto apreciado pelos animais domésticos, silvestres e peixes.

Apesar da importância do jenipapo e do bacuri, essas espécies se apresentam com "média" abundância nas comunidades visitadas. Entretanto, há que se considerar que a ocorrência de poucas unidades de árvores frutíferas, normalmente localizadas em quintais e de uso doméstico, é suficiente para a manutenção das necessidades dos ribeirinhos.

Dubois (1996) identificou diversas espécies de uso nãomedeireiro e de importância para populaçôes ribeirinhas, além do jenipapo e bacuri, o ingá, castanha-sapucaia e taperebá, espécies também identificadas neste estudo.

De uso múltiplo e intenso pelas populaçôes locais, as espécies do grupo $G_{4}$, são muito utilizadas pela população local, segundo os entrevistados. A embaubeira, sapupireira e açacuzeiro destacam-se principalmente pelas propriedades medicinais. A embaubeira é utilizada pelos ribeirinhos como abortiva para animais, além de acelerar o trabalho de parto ao expulsar a placenta rapidamente (Raintree Nutrition, 2004). A sapupireira é reconhecidamente um poderoso antihelmíntico (Marín \& Flores, 2003), muito utilizado na região. $\mathrm{O}$ açacuzeiro é considerado anti-inflamatório e antihelmíntico, cujo emprego exige muita cautela por sua ação tóxica (Plantamed, 2008).

Essas espécies, além da função medicinal, juntamente com a tamanqueira têm função madeireira. $\mathrm{O}$ açacuzeiro, sapupireira e tamanqueira têm seus troncos muito utilizados na construção de cercas, currais e obras leves e temporárias, para lenha (Provarzeas, 2008) e a árvore, muito apreciada por sua sombra. As espécies do grupo $\mathrm{G}_{4}$ se apresentam, na região em estudo, em "grande" abundância, o que denota racionalidade no uso dessas espécies pelas populações locais.

O agrupamento de usos $G_{5}$ está focado para o uso da madeira do paricazeiro, pau mulateiro e taxizeiro, espécies cuja madeira é utilizada na propriedade para lenha, construção de curais, cercas, palhoças e outros. O taxizeiro é considerado uma alternativa sustentável para a produção de lenha pelo rápido crescimento (Souza et al., 2004). As espécies desse grupo apresentaram "média" abundância para a região estudada, provavelmente pela funçâo madeireira com exploração mais intensa pelo extrativismo.

Vale ressaltar que segundo as informaçóes coletadas, a exploração madeireira dessas espécies, pelos ribeirinhos, objetiva somente o uso na propriedade, sem fins comerciais, apesar de seu valor no mercado. Isso mostra claramente que o interesse dos ribeirinhos está focado em espécies arbóreas que forneçam produtos de uso múltiplo e que venham a satisfazer suas necessidades básicas de sobrevivência, sem demonstrar também grande interesse nas questōes ecológicas, econômicas ou sociais.

De maneira geral, a ocorrência das espécies florestais nas áreas ribeirinhas pesquisadas, segundo os entrevistados, se apresentou de "grande" abundância. A maioria das espécies classificadas como de "pequena" abundância, são destinadas a alimentaçấo animal e medicina popular. Claro-Junior $e t$ al. (2004) destacam que redução na oferta de frutos, sementes e outras formas de matéria orgânica originada da floresta ocasiona mudanças nos hábitos alimentares dos peixes e animais silvestres, por constituírem sua cadeia alimentar.

Além disso, é importante lembrar que os animais podem atuar como agentes de dispersáo de sementes contribuindo para a conservação da biodiversidade do ecossistema (Aquino et al., 2007). A dispersão de sementes biótica é um processo ecológico fundamental para a manutenção das florestas tropicais (Souza, 2002) pela integração planta e animal. Algumas espécies de peixes, como o tambaqui (Colossoma macropomum), são agentes dispersores importantes em ambientes inundáveis (Souza, 2002).

A abundância de uma espécie vegetal nas planícies fluviais pode estar relacionada a uma série de fatores, dentre os quais: taxa germinação das sementes e sobrevivência de mudas sob anoxia/hipoxia temporária, a eficiência dos dispersores, a forma de exploração desses recursos naturais pelas populaçôes tradicionais e intensidade desses eventos.

\section{CONCLUSÕES}

1. As frutíferas de uso alimentício, humano e animal, são as espécies florestais preferidas pelos ribeirinhos, seguidas pelas árvores com fins madeireiros;

2. O interesse dos ribeirinhos está focado para espécies arbóreas que forneçam produtos de uso múltiplo que satisfaçam suas necessidades básicas de sobrevivência;

3. A ocorrência da maioria das espécies florestais nas comunidades ribeirinhas pesquisadas, segundo os entrevistados, apresenta "grande" abundância.

\section{BIBLIOGRAFIA CITADA}

Almeida, S. S. de; Amaral, D. D. do; Silva, A. S. L. da. 2004. Análise florística e estrutura de florestas de Várzea no estuário amazônico. Acta Amazonica, 34: 513-524.

Aquino, F. de G.; Walter, B. M. T.; Ribeiro, J.F. 2007. Espécies vegetais de uso múltiplo em reservas legais de cerrado - Balsas, Ma. Revista Brasileira de Biociências, 5: 147-149. 
Araújo, E.A. de; Rocha, M.M.V. 2007. Competência Informacional: Perfil dos profissionais da informação - bibliotecário de instituiçôes de ensino superior privado do município de João Pessoa-PB. (www.snbu2006.ufba.br/soac/viewpaper.php). Acesso em: 29/03/2007.

Arruda, R. 1997. Populaçóes tradicionais e a proteçáo dos recursos naturais em unidades de conservação, p. 262-276. In: Congresso brasileiro de unidades de conservação, 1., Curitiba. Anais... Curitiba, 1997.

Bittencourt, M.M.; Amadio, S.A. 2007. Proposta para identificação rápida dos períodos hidrológicos em áreas de várzea do rio Solimôes-Amazonas nas proximidades de Manaus. Acta Amazonica, 37: 303-308.

Canto, O. do. 2007. Várzea e varzeiros da amazônia. Museu Paraense Emílio Goeldi, Coleção Eduardo Galvão, Belém, PA. 167 pp.

Claro-Junior, L.; Ferreira, E.; Zuanon, J.; Araujo-Lima, C. 2004. O efeito da floresta alagada na alimentação de três espécies de peixes onívoros em lagos de várzea da Amazônia Central, Brasil. Acta Amazonica, 34: 133-137.

Costa, P.A. da. 2008. Sabores da beira do rio e da mata. Faculdade de Engenharia de Alimentos, Campinas. (http://www.fea.unicamp. br/ site/index.php/documento7). Acesso em: 08/04/2008.

Dias-Filho, M. B. 2007. Degradação de pastagens: processos, causas e estratégias. Embrapa Amazônia Oriental, Belém, PA. 190 pp.

Dubois, J.C.L. 1996. Utilizaçâo do potencial extrativista das florestas amazônica: soluçóes encontradas pelo homem na Amazônia. Universidade Federal Rural, Rio de Janeiro, RJ. 13 pp.

Falesi, I.C.; Silva, B.N.R. da. 1999. Ecossistemas de várzeas da regiāo do Baixo Amazonas. Embrapa Amazônia Oriental, Belém, PA. $75 \mathrm{pp}$.

Franke, I.L.; Lunz, A.M.P.; Amaral, E.F. 2000. Metodologia para planejamento, implantação e monitoramento de sistemas agroflorestais: um processo participativo. (Embrapa Acre. Documentos, 49), Embrapa Acre, Rio Branco, AC. 35 pp.

Garrafiel, D.R.; Nobre, F.R.C.; Dain, J. 1999. Manual da metodologia pesa: uma abordagem participativa. PESAGRE, Rio Branco, AC. 33 pp.

Goulding, M.; Smith, N.J.H.; Mahar, D.J. 1996. Floods of fortune: ecology and economy along the Amazon. New York, Columbia University Press. 193 pp.

Grenier, L. 1999. Conocimiento indígena: guia para el investigador. 1999. Centro Internacional de Investigaciones para el Desarrollo, Ottawa. (http://www.idrc.ca/openebooks/891-0/). Acesso em: 19/04/2008

Homma, A.K.O. 1998. Amazônia: meio ambiente e desenvolvimento agrícola. Embrapa-SPI, Brasília, DF. 412 pp.

Huxley, P. 1999. Classifying multipurpose trees: what are functional types? p. 164-184. In: Huxley, P. (Ed). Tropical agroforestry.

Johnson, R.A.; Wichern, D. W. 1998. Applied multivariate statistical analysis. New Jersey, Prentice Hall. 815 pp.

LBASANTARÉM. 2006. Dados meteorológicos. Santarém, 20022006. (ftp://boojum.asrc.cestm.albany.edu/pub/lba/metstat/ embrapa.daily.2002.dat). Acesso em: 30/08/2006.
Lima, D. 2005. Desenvolvimento socioambiental nas várzeas dos rios Amazonas e Solimóes: perspectivas para o desenvolvimento da sustentabilidade. Manaus, AM. 416 pp.

Manly, B.F.J. 1994. Multivariate statistical methods: a primer. Chapman \& Hall, London. 215 pp.

Marín, W.A.; Flores, E.M. 2003. Andira Inermis (W. Wrigth) Kunth Ex DC. Costa Rica.(http://www.rngr.net/publications/ttsm/ folder.2003-07-11.4726/andira\%20inermis.pdf/file). Acesso em: 18/07/2008.

Montes, C.S.; Weber, J.C. 1997. Priorización de especies arbóreas para sistemas agroflorestales em la selva baja del Perú. Agroforesteria en las Américas, 4: 12-17.

Nair, P.K.R. 1993. An introduction to agroforestry. Kluwer Academic Publishers, The Netherlands. 499 pp.

PLANTAMED. Hura Crepitans L. - Açacu. 2008. http://www. plantamed.com.br/plantaservas/especies/Hura_crepitans.htm. Acesso em: 03/01/2008.

Projeto Iara. 1996. Algumas consideraçóes sobre a atual situação da mata ciliar na área do projeto Iara. Mimeo, Santarém, 24 pp.

PROVÁRZEAS. 2008. Relatório síntese dos estudos estratégicos sobre os setores florestal e agropecuário: manejo florestal da várzea. Manaus. (www.ibama.gov.br/provarzea/download. php?id_download=410). Acesso em: 02/072008.

Queiroz, H.L.A. 2005. Reserva de desenvolvimento sustentável Mamirauá. Estudos Avançados, 19: 183-202.

RAINTREE NUTRITION. 2004. Ethnomedical Information On Embauba (Cecropia Obtusifolia). Inc. Carson City, NV. (http:// www.rain-tree.com/embauba-traditional-uses.pdf). Acesso em: $10 / 07 / 2008$

Salvador, J. do L.G. 1986. Comportamento de espécies florestais nativas em áreas de depleção de reservatórios. IPEF, 33: 73 78.

SAS INSTITUTE. 1990. Sas/Stat. User's Guide. Version 6. 4th Ed. Cary, Nc, v.2, 846 pp.

Semedo, R.J. da C.G.; Barbosa, R.I. 2007. Árvores frutíferas nos quintais urbanos de Boa Vista, Roraima, Amazônia Brasileira. Acta Amazonica, 37: 497-504.

Sheil, D.; Puri, R.K.; Basuki, I.; Van Heist, M.; Wan, M.; Liswanti, N.; Sardjono, M.A.; Samsoedin, I.; Sidiyasa, K.; Permana, E.; Angi, E.M.; Gatzweiler, F.; Johnson, B.; Wijaya, A. 2003. Exploring biological diversity, environment and local people's perspectives in forest landscapes: Methods for a multidisciplinary landscape assessment. CIFOR, Jakarta. 106 pp.

Siqueira, H.M. de. 2008. Importância Das Plantas Medicinais. (http://www.ufes.br/ proex/arquivos/importancia_das_ plantas_medicinais.pdf). Acesso em: 19/07/2008.

Souza, de C.R.; Lima, R.M.B. de; Azevedo, C.P. de; Rossi, L.M.B. 2004. Seleção de espécies florestais para utilização em sistemas agroflorestais. In: Congresso Brasileiro de Sistemas Agroflorestais, 5., SAFS Desenvolvimento Com Proteçáo Ambiental: Anais, Curitiba: SBSAF, 2004.

Souza, L.L. de. 2002. Reserva Amanã: a dispersão de sementes por animais ajuda na preservação das florestas. O Macaqueiro, 15(1). 
(http://www.mamiraua.org.br/macaqueiro/art_manejo/n15. htm). Acesso em: 28/06/2008.

Statsoft Inc. Statistica. 2001. Data analysis software system, Version 5.5. (www.statsoft.com). Acesso em: 02/02/2007.

Veiga, J.B. da; Alves, C.P.; Marques, L.C.T.; Veiga, D.F. da. 2000. Sistemas silvipastoris na Amazônia Oriental. (Embrapa Amazônia Oriental. Documentos, 56).Embrapa Amazônia Oriental. Belém, PA. 62 pp.

Recebido em: 27/08/2008

Aceito em: 14/04/2009 